\title{
REDUÇÃO DO INDICE DE DESCLASSIFICAÇÃO DE TARUGO NA ACIARIA DE LONGOS DA CSN*
}

\author{
Julio Cesar Correa de Oliveira ${ }^{1}$ \\ Tiago Seixas Bittencourt ${ }^{2}$ \\ Marciel Belligoli ${ }^{3}$ \\ Fernando Souza Candido ${ }^{4}$
}

\section{Resumo}

O processo de lingotamento contínuo em uma aciaria elétrica é responsável pela solidificação do aço líquido proveniente das ações de fusão e refino no forno elétrico a arco, e ajuste de composição química no forno panela. Tal processo é crítico, pois, há eclosão de defeitos que estão associados às etapas anteriores como também da própria solidificação. Alguns destes defeitos são: trincas, romboidade, segregações, porosidade, dentre outros. Tais defeitos podem vir a desclassificar o tarugo quanto a sua qualidade, 0 que prejudica 0 volume e custos da produção, afeta consideravelmente a distribuição de material para a laminação e diminuindo a produtividade. Dentre os defeitos expostos no texto, porosidade foi classificada como uma das principais causas, na desclassificação do tarugo. O artigo a seguir analisou o fenômeno de nucleação do defeito, de forma a desenvolver ações corretivas, por meio de ferramentas de gerenciamento. $O$ resultado alcançado através das medidas tomadas permitiu a redução de defeitos, na ordem de $50 \%$.

Palavras-chave: Porosidade; Qualidade; Tarugo.

\section{REDUCTION OF CONTENTS OF DISQUALIFICATION OF BILLETS IN THE STEEL MILL OF LONG CSN}

\section{Abstract}

The continuous casting process in an electric steel plant is responsible for solidifying the liquid steel from the actions melting and refining in electric arc furnace, and adjust chemical composition of the ladle furnace. This process is critical since there outbreak of defects that are associated with the earlier steps as well as the solidification itself. Some of these defects are cracks, rhomboidity, segregation, porosity, among others. Such defects are likely to disqualify the billet as their quality, which undermines the volume and costs of production, significantly affects the distribution of material for laminating and decreasing productivity. Among the flaws exposed in the text, porosity was classified as major causes in the disqualification of the billet. The following article has analyzed the phenomenon of nucleation of the defect in order to develop corrective actions, by means of management tools. The result achieved by the actions taken allowed the reduction of defects in the order of $50 \%$.

Keywords: Porosity; Quality; Billet.

Engenheiro de Desenvolvimento, Companhia Siderúrgica Nacional (CSN), Volta Redonda, RJ, Brasil.

Engenheiro Especialista, Companhia Siderúrgica Nacional (CSN), Volta Redonda, RJ, Brasil.

Especialista em Siderurgia, Companhia Siderúrgica Nacional (CSN), Volta Redonda, RJ, Brasil.

Gerente Geral de Produção de Aços Longos, Companhia Siderúrgica Nacional (CSN), Volta Redonda, RJ, Brasil. 


\section{INTRODUÇÃO}

\subsection{Porosidades nos Tarugos}

Na prática de produção de aço em aciarias elétricas, o aço líquido é exposto a gases durante a fusão da carga metálica e no refino. Tais gases são o oxigênio e gás natural, utilizados nos queimadores para auxiliar na fusão da carga metálica e o monóxido de carbono que é formado no processo, cujo mesmo, também pode vir a se solubilizar no aço líquido, combinado com o oxigênio do banho, formando o dióxido de carbono, gás que também se solubiliza. O contato com a atmosfera durante o vazamento da panela para o distribuidor e deste para os moldes (lingotamento contínuo) também expõe o aço líquido ao nitrogênio e oxigênio. Tais elementos conseguem permanecer diluídos no aço líquido, pois sua solubilidade é alta neste. Com a solidificação no processo de lingotamento contínuo, estes gases devidos sua reduzida solubilidade no sólido, tendem a se concentrar no líquido remanescente, gerando como consequência a formação de poros. Tais poros podem ser classificados como poros superficiais e poros internos

Poros superficiais (pin holes) apresentam formação de óxidos na superfície interna e alguma descarbonetação na matriz metálica ao redor. A oxidação da superfície prejudica o caldeamento durante a laminação, originando trincas, pela concentração de tensão originada pela área superficial do poro.

Poros internos (blow holes) são formados pelo monóxido de carbono (CO), nitrogênio gasoso $\left(\mathrm{N}_{2}\right)$ ou hidrogênio $\left(\mathrm{H}_{2}\right)$, solubilizados durante o processamento do aço líquido no lingotamento contínuo e que afloram a superfície, na etapa de reaquecimento do tarugo na laminação, originando trincas.

As porosidades podem ser observadas por intermédio de análise macrográfica, conforme a figura 1 .

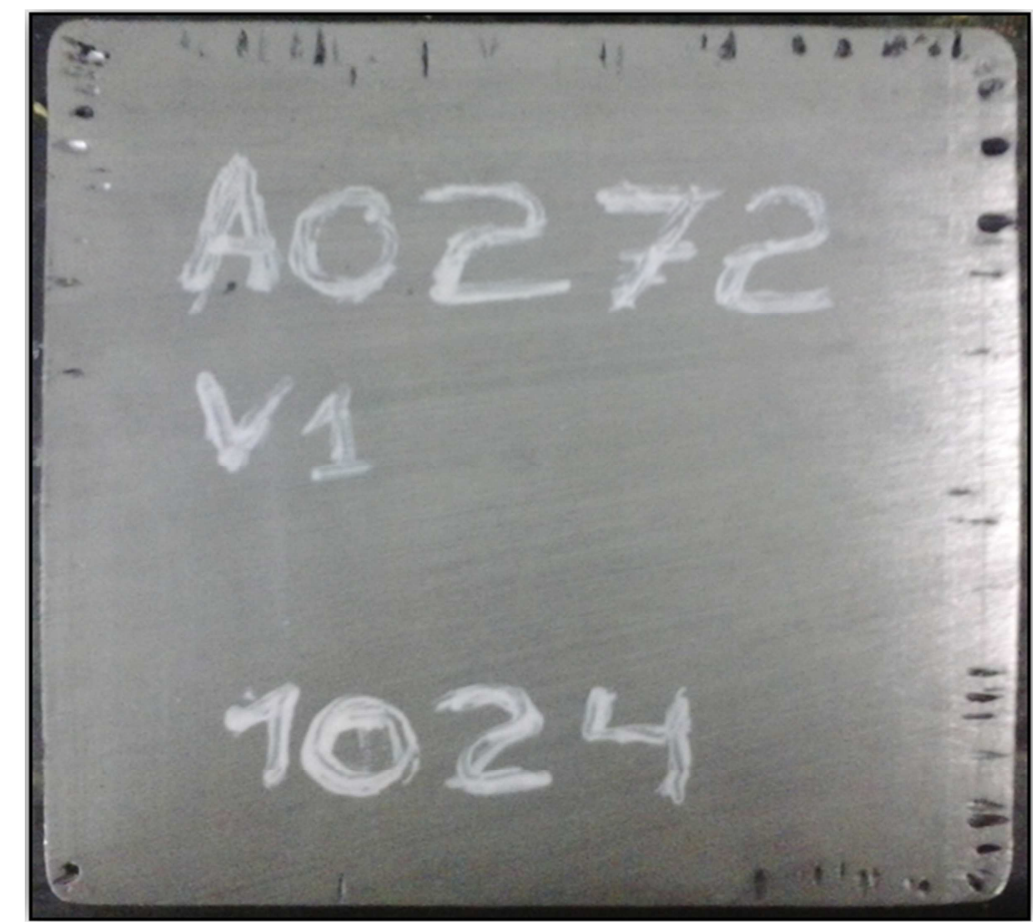

Figura 1. Análise macrográfica mostrando blowholes em um tarugo. 


\subsection{Teoria de Formação da Bolha}

O fenômeno de formação da bolha pode ser explicado pela teoria da pressão total e da pressão máxima, dos gases formadores de bolhas. A pressão total é definida na figura 2.

$$
P_{\text {Toal }}=P_{A}+P_{F}+\frac{2 \sigma}{r}
$$

Figura 2. Pressão total

Onde:

$\mathrm{P}_{\mathrm{A}}=$ pressão atmosférica;

$\mathrm{P}_{\mathrm{F}}=$ pressão ferrostática;

$2 \sigma / r=$ tensão superficial e raio da bolha.

Para que ocorra formação da bolha, o somatório das pressões exercidas pelos gases deve ser maior que a pressão total, conforme pode ser observado na Figura 3:

$$
\mathrm{P}_{\text {gas }}^{\max }=\mathrm{P}_{\mathrm{H}_{2}}^{\max }+\mathrm{P}_{\mathrm{N}_{2}}^{\max }+\mathrm{P}_{\text {CO }}^{\max }>\mathrm{P}_{\text {Tocal }}
$$

Figura 3. Condição de formação da bolha.

O efeito da tensão superficial é insignificante para a pressão total, visto que para uma bolha de 1,0 mm de diâmetro, essa tensão tem o valor de 0,02 a 0,03 atm, que não se compara ao tamanho das porosidades formadas no lingotamento contínuo.

Nos primeiros estágios do lingotamento contínuo, ocorre a formação de porosidades subsuperficiais, a uma pequena distância abaixo do menisco, onde a pressão total é levemente superior à pressão atmosférica. Neste estágio, pode-se considerar o valor da pressão total de 1,05 atm. Tal pressão é a crítica para a formação de blowholes.

A pressão ferrostática aumenta à medida que se afasta do menisco, onde chega à $0,5 \mathrm{~atm}$ na saída do molde. Por essa razão, é comum identificar porosidades no tarugo, até uma pele de espessura de 10 a $12 \mathrm{~mm}$, e quando somada à pressão atmosférica, resulta no valor de pressão total de 1,5 atm. Esse valor ultrapassado pela soma das pressões parciais dos gases hidrogênio, nitrogênio e monóxido de carbono em equilíbrio com o aço líquido, resulta na formação de bolhas e poros no tarugo solidificado.

\section{MATERIAL E MÉTODOS}

\subsection{Metodologia}

Primeiramente foi escolhida a metodologia para condução do trabalho, onde o método de gerenciamento PDCA, foi escolhido. Na figura 4, pode ser visto o ciclo PDCA com suas subdivisões de acordo com a fase do ciclo. 


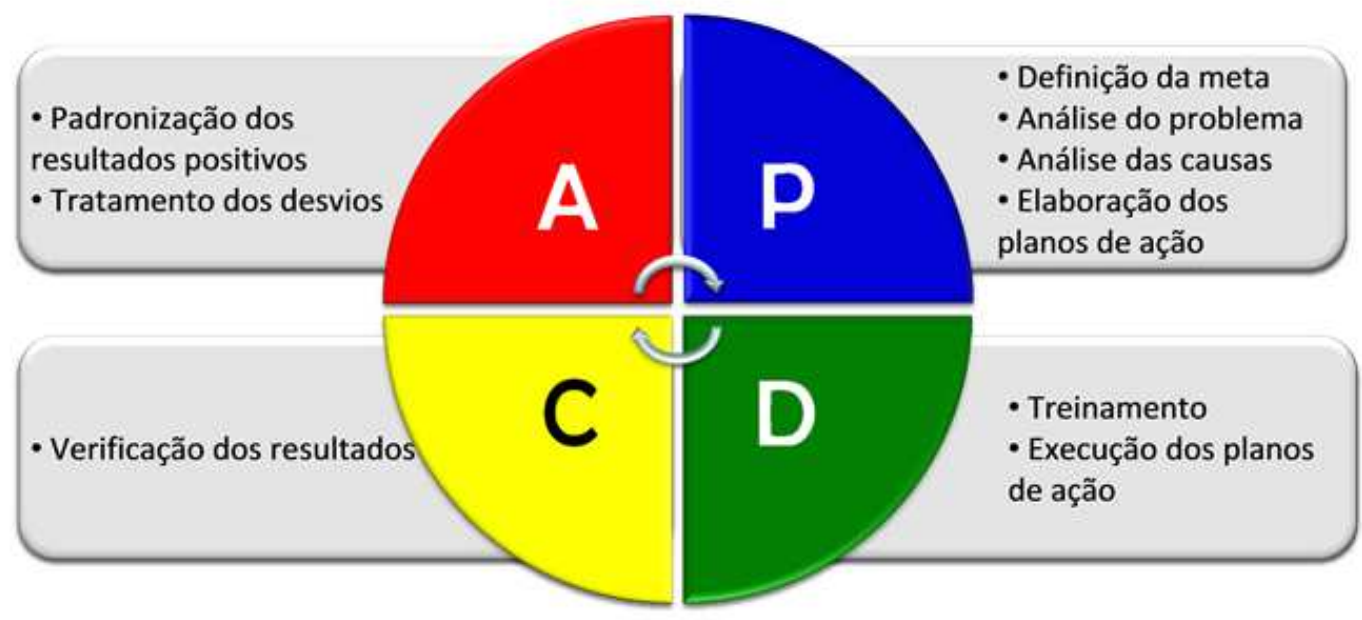

Figura 4. Ciclo PDCA.

$\mathrm{Na}$ etapa seguinte, foi feito um brainstorming sobre o problema relacionado aos blowhole, para se ter uma visão geral do problema. O brainstorming foi dividido em mão de obra, medida, material, máquina, material, meio ambiente e método. A figura 5 mostra os resultados das idéias expostas.

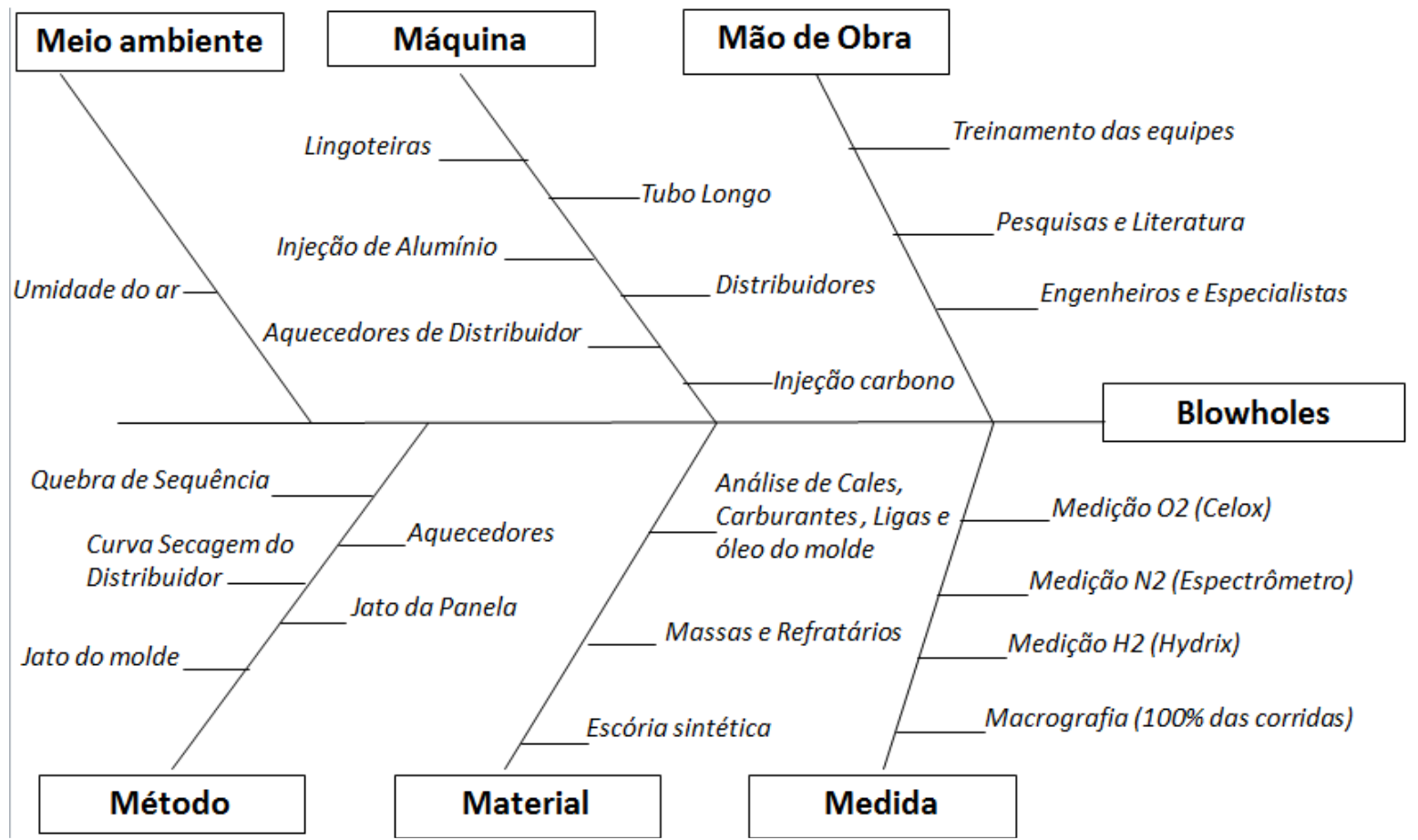

Figura 5. Resultado do brainstorming exposto da forma espinha de peixe.

\subsection{Coleta de Dados}

O primeiro passo após o brainstorming foi a coleta dos dados relacionados às causas dos blowholes, medição do teor dos gases responsáveis pela nucleação de porosidades e bolhas nos tarugos que resultam em trincas que desclassificam 0 material quanto a sua qualidade. A mediação de $\mathrm{O}_{2}$ foi feita via Celox, conforme mostra a figura 6 , a medição do $\mathrm{H}_{2}$, foi realizada pelo sistema Hydris, mostrado na figura 7 e a análise do $N_{2}$, foi realizada pelo espectrômetro de emissão ótica e 
verificado seus resultados, através de análise estatística, conforme mostra a figura 8. Também foram feitos análise macrográfica de todos os tarugos desde o início dos testes, para se ter dados específicos sobre como o defeito se apresenta e mensurar a quantidade de blowholes.

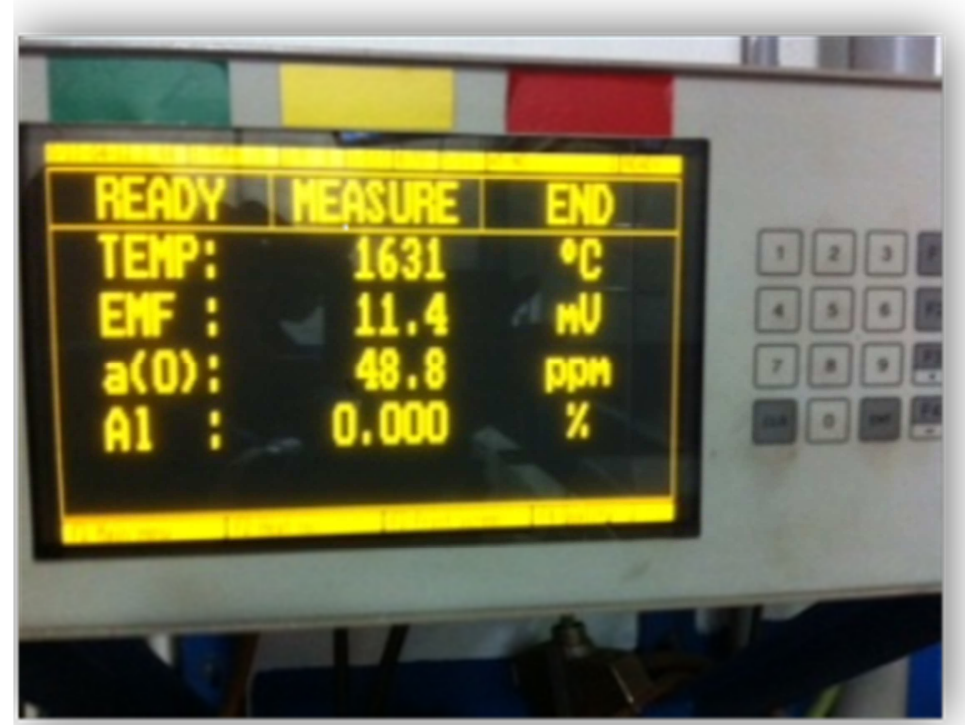

Figuras 6. Tela de observação de resultado de medições de oxigênio, Celox.

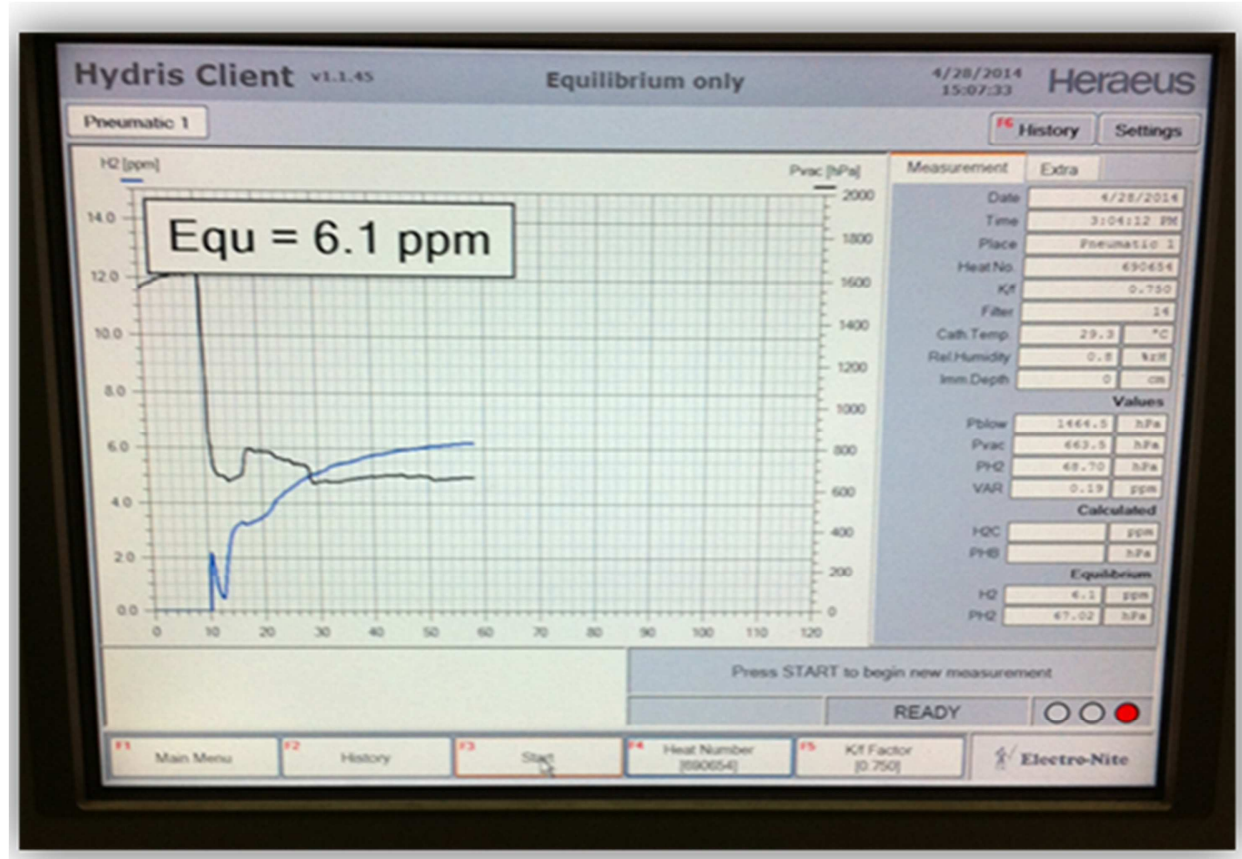

Figuras 7. Tela de observação de resultados de hidrogênio, Hydris. 


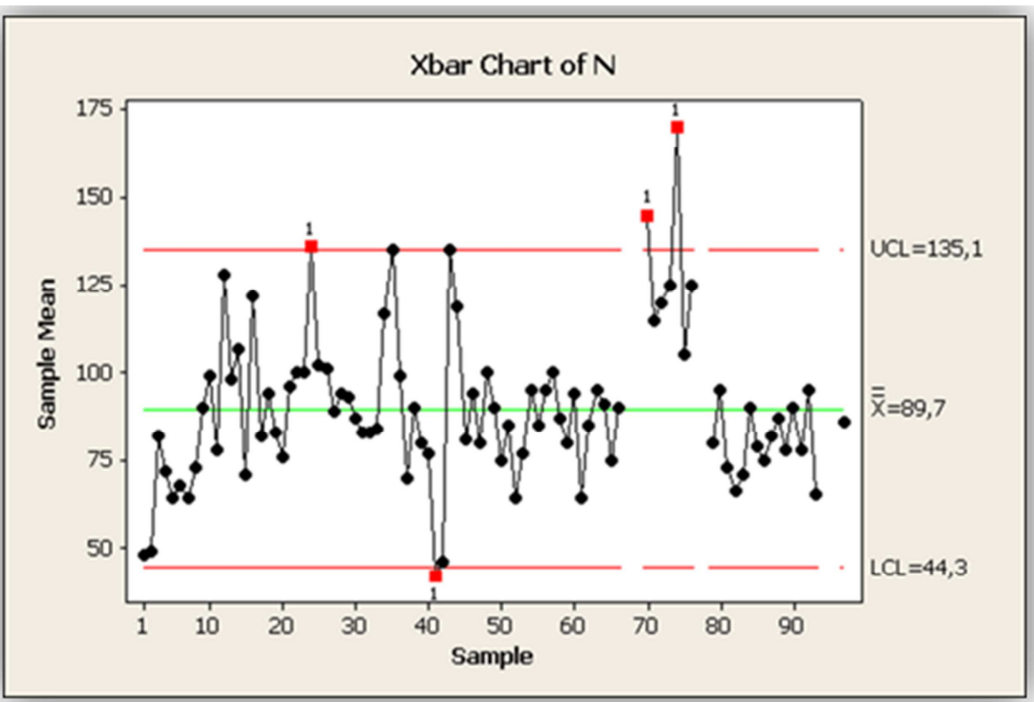

Figuras 8. Resultado da análise estatística da medição de $\mathrm{N}_{2}$.

\subsection{Mão de Obra}

No que tange às equipes relacionadas ao trabalho, foram feitos treinamentos relacionados ao problema de porosidades por uma revisão e pesquisa, sobre teorias e práticas voltadas para esse fim. Relatórios de caracterização foram feitos com base no índice de reprovação dos vergalhões que apresentaram blowholes em seus tarugos de origem, mostrando qual a consequência dos blowholes no produto acabado. Uma folha de verificação foi elaborada para se ter o controle de como a corrida estava sendo processada na etapa de lingotamento contínuo. Tal controle continha um questionário que teria que ser preenchido pelo operador a cada processamento de corrida feito no lingotamento contínuo, contendo respostas rápidas de sim ou não e desvio observado (caso ocorresse). Um questionário semelhante também foi repassado às equipes de operação do forno panela, mas com perguntas relacionadas ao processamento neste sistema. Todos os sistemas, forno elétrico a arco, forno panela e lingotamento contínuo, foram acompanhados de perto pela equipe com o plano de acompanhamento experimental, onde continha cada atividade que deveria ser feita e ainda uma tabela de anotações para os testes que levavam as adições de materiais, como a escória sintética, cuja função era de controle na elevação da concentração $\mathrm{H}_{2}$.

\subsection{Material}

No quesito materiais, foram feitas análises de cales, ligas, carburantes, palha de arroz, óleo de lubrificação do molde, refratários e escória sintética. Tais materiais estavam sendo adicionados nos testes ou eram usadas rotineiramente nas atividades. As análises buscavam o percentual de umidade que os materiais apresentavam, pois a elevada umidade aumenta o risco de blowholes pelo aumento no teor de hidrogênio no aço.

\subsection{Maquinário}

Nesta etapa foram avaliadas as máquinas responsáveis pelo processamento do aço durante a corrida, e o que poderia ser feito nestas unidades para se reduzir o surgimento de blowholes, mas também para padronização de processos e aumento 
de produtividade. Foi definida a necessidade de injeção de fios de alumínio no molde, como mostra a figura 9, para garantir uma melhora na desoxidação do aço na linha do lingotamento contínuo, diminuindo $o$ teor de oxigênio e consequentemente a formação de gases nucleadores de blowholes. Uma adequação nas estações de secagem/aquecimento do distribuidor (figura 10) foi proposta para garantia da sua eficiência. Outras adequações também foram definidas, como a utilização de tubo longo, dentre outros.

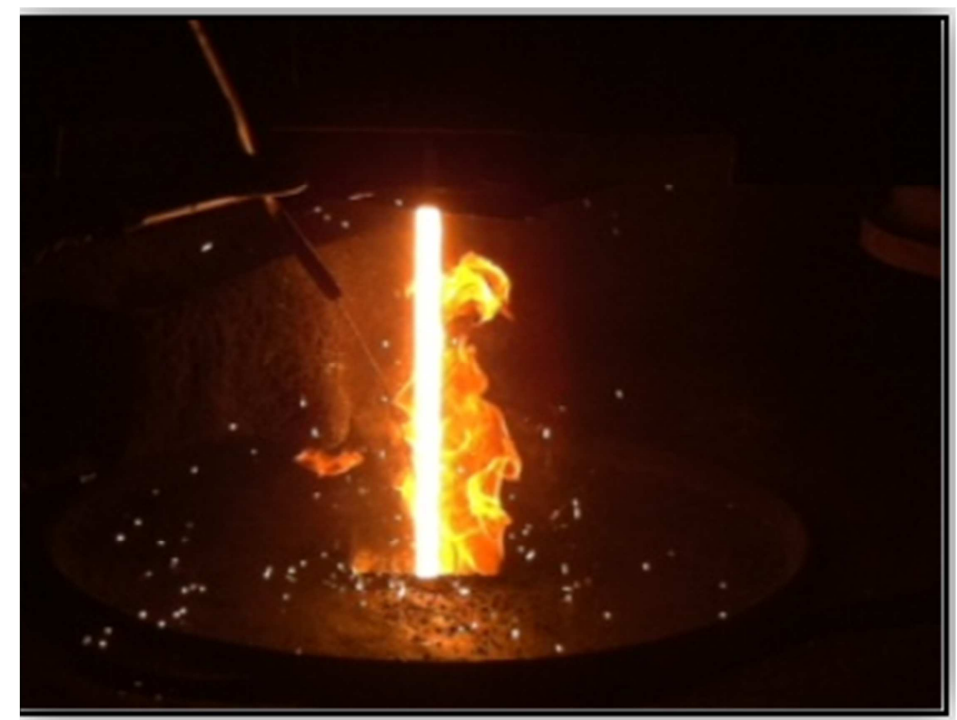

Figura 9. Injeção de alumínio no molde, lingotamento contínuo.

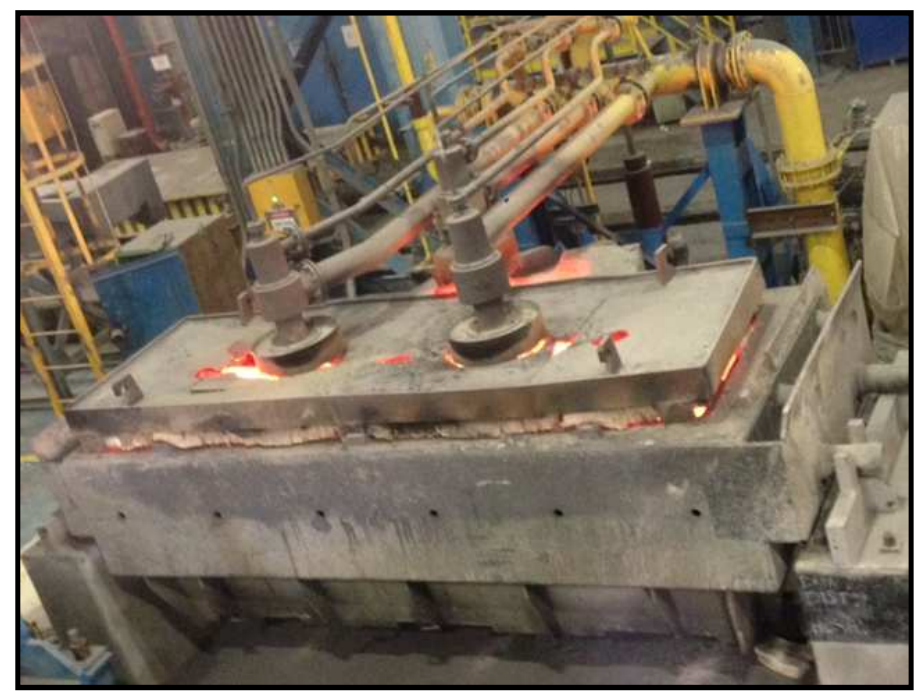

Figura 10. Adequação no sistema de aquecimento dos distribuidores.

\subsection{Métodos}

Foram definidas uma série de adequações em diversos equipamentos. Uma das definições foi aumentar o sequenciamento e evitar quebra de ritmo no processo da aciaria, para um aumento na produtividade e evitar que o aço líquido fique exposto à atmosfera, conforme mostra a figura 11, pelo período de quebra de sequência. Isto foi alcançado pela manutenção constante do fluxo de aço, mantendo-o coerente pela redução do diâmetro interno da válvula da panela. 


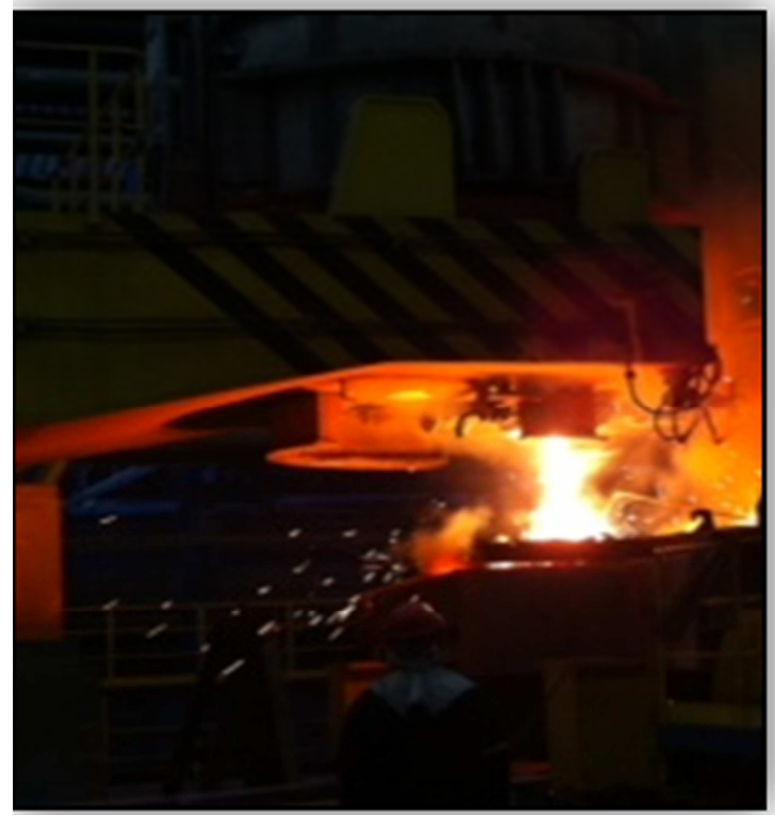

Figura 11. Adequação no jato da panela para o distribuidor.

\subsection{Plano de Ação}

Tal plano de ação foi levantado após o brainstorming usando o sistema $5 \mathrm{~W} 1 \mathrm{H}$ de gerenciamento, que atua de maneira prática e direta nas pendencias levantadas. Detalhes do plano são mostrados nas figuras 12 e 13.

\begin{tabular}{|c|c|c|c|c|c|}
\hline O quê? & Porquê? & Como? & Onde? & Quem? & Quando? \\
\hline $\begin{array}{l}\text { Padronização do } \\
\text { processo Forno } \\
\text { Panela }\end{array}$ & $\begin{array}{l}\text { Garantir não } \\
\text { reincorporação de } \\
\text { gases no aço liquido }\end{array}$ & $\begin{array}{l}\text { Padronizando rotina } \\
\text { e procedimentos } \\
\text { operacionais e } \\
\text { treinando a operação }\end{array}$ & $\begin{array}{l}\text { Aciaria-Forno } \\
\text { Panela }\end{array}$ & Julio & Fevereiro / 2014 \\
\hline $\begin{array}{l}\text { Analise da umidade } \\
\text { das Ligas, Cales e } \\
\text { Carburantes, óleo e } \\
\text { demais insumos. }\end{array}$ & $\begin{array}{l}\text { Avaliar a umidade } \\
\text { dos insumos como } \\
\text { possível fonte de } \\
\text { Hidrogênio }\end{array}$ & $\begin{array}{l}\text { Coletando amostras } \\
\text { para analise } \\
\text { laboratorial e } \\
\text { determinação de } \\
\text { umidade }\end{array}$ & $\begin{array}{l}\text { Aciaria - Cal e Ligas / } \\
\text { Forno Panela }\end{array}$ & Julio / Tiago & Fevereiro / 2014 \\
\hline $\begin{array}{l}\text { Introdução da escória } \\
\text { sintética no processo } \\
\text { de Aciaria }\end{array}$ & $\begin{array}{l}\text { Melhorar processo } \\
\text { de escorificaçãoe } \\
\text { consequentemente } \\
\text { desoxidação do aço }\end{array}$ & $\begin{array}{l}\text { Providenciando lotes } \\
\text { de escoria sintetica } \\
\text { para aplicação na } \\
\text { panela. }\end{array}$ & $\begin{array}{l}\text { Aciaria-Forno } \\
\text { Panela }\end{array}$ & Tiago / Julio & Fevereiro / 2014 \\
\hline $\begin{array}{l}\text { Analise de Oxigênio, } \\
\text { Nitrogênio e } \\
\text { Hidrogênio no aço } \\
\text { liquido }\end{array}$ & $\begin{array}{l}\text { Medir a presença dos } \\
\text { gases geradores de } \\
\text { Blowholes no aço } \\
\text { liquido }\end{array}$ & $\begin{array}{l}\text { Equipamentos } \\
\text { específicos para } \\
\text { analises. } \\
\text { Espectrômetro/Celox } \\
\text { /Hydrix }\end{array}$ & $\begin{array}{l}\text { Aciaria - Forno } \\
\text { Panela / } \\
\text { Lingotamento }\end{array}$ & $\begin{array}{l}\text { Ademir / Julio / Tiago } \\
\text { / Celio }\end{array}$ & Janeiro à Abril / 2014 \\
\hline Análise Macrográfica & $\begin{array}{l}\text { Analise dos defeitos } \\
\text { em tarugos e } \\
\text { levantamento de } \\
\text { dados }\end{array}$ & $\begin{array}{l}02 \text { amostras por } \\
\text { corrida / } 100 \% \text { das } \\
\text { corridas }\end{array}$ & Laboratório Macro & Ademir / Pitias & Janeiro/ 2014 \\
\hline $\begin{array}{l}\text { Controle de liberação } \\
\text { de corridas para } \\
\text { Laminação }\end{array}$ & $\begin{array}{l}\text { Filtrar a liberação de } \\
\text { corridas para } \\
\text { Laminação. }\end{array}$ & $\begin{array}{l}\text { Padronização dos } \\
\text { critérios de liberação } \\
\text { de corridas para } \\
\text { Laminação }\end{array}$ & Laboratório Macro & Ademir / Pitias & Janeiro / 2014 \\
\hline $\begin{array}{l}\text { Aquecedor do } \\
\text { distribuidor }\end{array}$ & $\begin{array}{l}\text { Garantir } \\
\text { aquecimento e } \\
\text { secagem correta do } \\
\text { distribuidor }\end{array}$ & $\begin{array}{l}\text { Melhorando a chama } \\
\text { do aquecedor e } \\
\text { providenciando } \\
\text { recursos para } \\
\text { combustão na sola } \\
\text { do distribuidor }\end{array}$ & $\begin{array}{l}\text { Aciaria - Refratário / } \\
\text { Lingotamento }\end{array}$ & Celio / Jouseberson & Abril / 2014 \\
\hline
\end{tabular}

Figura 12. Plano de ação 


\begin{tabular}{|c|c|c|c|c|c|}
\hline O quê? & Porquê? & Como? & Onde? & Quem? & Quando? \\
\hline $\begin{array}{l}\text { Injeção de Alumínio } \\
\text { no molde }\end{array}$ & $\begin{array}{l}\text { Garantir desoxidação } \\
\text { do aço no LC }\end{array}$ & $\begin{array}{l}\text { Providenciando } \\
\text { instalação da } \\
\text { maquina de injeção } \\
\text { de fios }\end{array}$ & $\begin{array}{l}\text { Aciaria - } \\
\text { Lingotamento }\end{array}$ & Celio /Julio & Abril / 2014 \\
\hline Inertização dos jatos & $\begin{array}{l}\text { Evitar reoxidação dos } \\
\text { jatos pela exposição } \\
\text { ao ambiente }\end{array}$ & $\begin{array}{l}\text { Providenciando } \\
\text { isolamento (Tubo } \\
\text { longo / Selagem) }\end{array}$ & $\begin{array}{l}\text { Aciaria - } \\
\text { Lingotmaento }\end{array}$ & $\begin{array}{l}\text { Celio / Sergio } \\
\text { Marinho }\end{array}$ & Maio / 2014 \\
\hline $\begin{array}{l}\text { Dreno na linha de gás } \\
\text { natural }\end{array}$ & $\begin{array}{l}\text { Purgar e drenar linha } \\
\text { de gás para controle } \\
\text { de umidade }\end{array}$ & $\begin{array}{l}\text { Instalação de dreno } \\
\text { na linha }\end{array}$ & $\begin{array}{l}\text { Aciaria - } \\
\text { Lingotamento }\end{array}$ & Celio & Março / 2014 \\
\hline $\begin{array}{l}\text { Redução do diâmetro } \\
\text { interno da válvula da } \\
\text { panela }\end{array}$ & $\begin{array}{l}\text { Diminuir o } \\
\text { estrangulamento da } \\
\text { válvula e garantir } \\
\text { maior coerência no } \\
\text { fluxo do jato para o } \\
\text { distribuidor }\end{array}$ & $\begin{array}{l}\text { Solicitando alteração } \\
\text { junto ao fornecedor }\end{array}$ & Aciaria - Refratário & $\begin{array}{l}\text { Julio / Celio / Tiago / } \\
\text { Jouseberson }\end{array}$ & Maio / 2014 \\
\hline $\begin{array}{l}\text { Aumentar } \\
\text { sequenciamento e } \\
\text { evitar quebra de } \\
\text { ritmo no processo de } \\
\text { Aciaria / Lingotar } \\
\text { com maior } \\
\text { velocidade }\end{array}$ & $\begin{array}{l}\text { Manter fluxo de aço } \\
\text { mais coerente, e } \\
\text { diminuir o tempo de } \\
\text { exposição do aço ao } \\
\text { ambiente/ Aumentar } \\
\text { utilização de } \\
\text { distribuidores e } \\
\text { reduzir seu consumo }\end{array}$ & $\begin{array}{l}\text { Garantir } \\
\text { sequenciamento de } \\
\text { corridas no LCe } \\
\text { evitar interrupções } \\
\text { de processo }\end{array}$ & Aciaria & GNA / GNT / GNM & Diariamente \\
\hline $\begin{array}{l}\text { Levantamentos } \\
\text { estatísticos e } \\
\text { monitoramento para } \\
\text { controles de } \\
\text { processo }\end{array}$ & $\begin{array}{l}\text { Monitoramento } \\
\text { estatístico de } \\
\text { processo e definições } \\
\text { de ações preventivas } \\
\text { e corretivas no } \\
\text { processo / } \\
\text { equipamentos }\end{array}$ & $\begin{array}{l}\text { Levantamento de } \\
\text { dados, analises, } \\
\text { literatura e debates } \\
\text { sobre as evidencias. } \\
\text { Definições dos } \\
\text { planos de ação }\end{array}$ & Aciaria & GNA / GNT & Diariamente \\
\hline
\end{tabular}

Figura 13. Plano de ação.

\section{RESULTADOS E DISCUSSÃO}

\section{1 Índice de desclassificação}

A figura 14 mostra as não conformidades devido ao defeito de blowholes no início dos testes, em janeiro, até julho, onde a campanha já estava consolidada.

\section{Não Conformidades - Blowholes 2014}

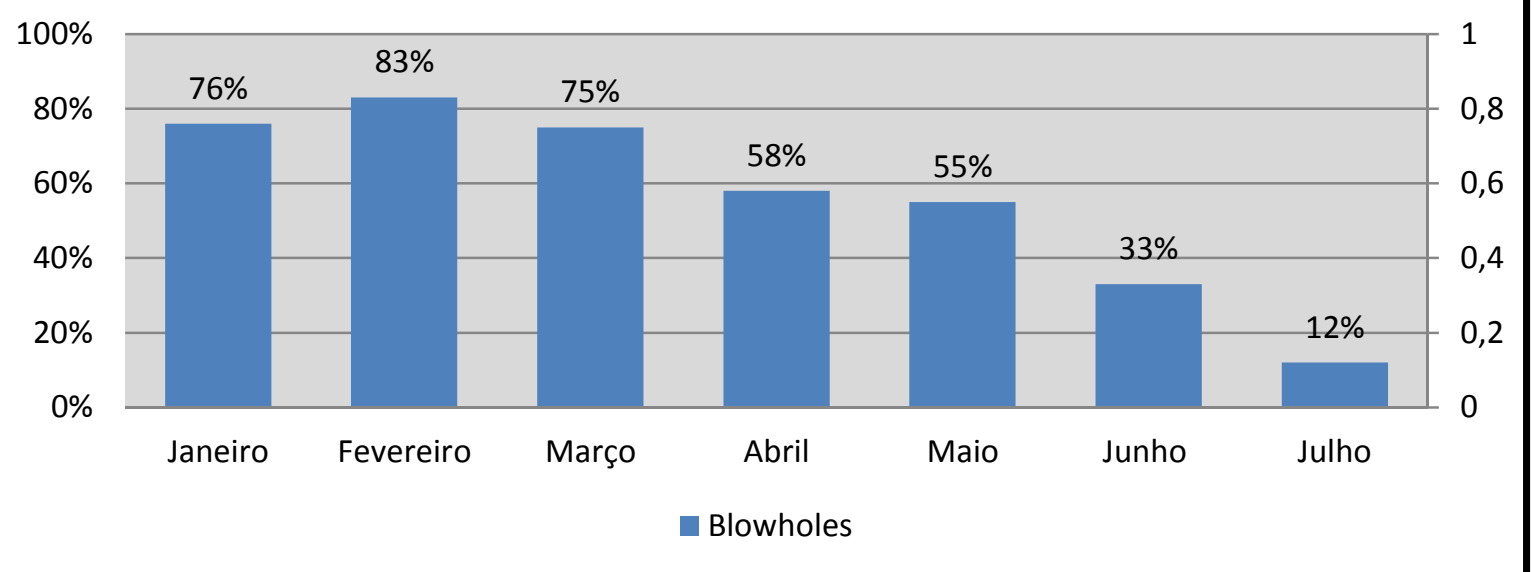

Figura 14. Não conformidades comparativas entre os meses de janeiro e julho de 2014. 
Pode ser observado que houve uma queda considerável na porcentagem de ocorrências de blowholes de janeiro a julho, mostrando a eficiência das técnicas usadas. Essa queda se deve a:

- Queda no teor dos gases formadores de bolhas e porosidades, $\mathrm{H}_{2}, \mathrm{~N}_{2}, \mathrm{CO}$, pela diminuição da umidade, uso de argônio para rinsagem e desoxidação do aço;

- Diminuição do tempo de exposição do aço líquido a atmosfera.

- Uso de escória sintética para melhor escorificação para a retirada de impurezas do aço.

- Controle da umidade dos insumos usados, cal, ligas, carburantes e palha de arroz e óleos de lubrificação.

Comparando o índice de blowholes dos meses anteriores podemos observar o decréscimo significativo na ocorrência, passando de $76 \%$ das corridas reprovadas para $12 \%$ das corridas reprovadas.

\section{CONCLUSÃO}

Vimos que o defeito de blowhole pode desclassificar demasiadamente a produção de uma aciaria elétrica. Cuidados devem ser tomados para controle no teor de gases dissolvidos no aço líquido, pois quando este se solidifica, tais gases confinados constituem nucleadores de trincas internas que comprometem a qualidade do produto acabado ao final da linha de laminação. A umidade é um fator que necessita ser controlado, pois o teor de hidrogênio deve ser mantido baixo para que não haja um aumento na pressão total dos gases, superando a pressão total e dando origem aos blowholes. Adequações na produção são também ótimas soluções, tanto para a produtividade como para diminuir o contato do aço líquido a atmosfera, diminuindo a oxidação da corrida e aumentando a qualidade do aço. Com todas essas medidas, a perda financeira é pequena, pois a desclassificação gera custos de produção e a adequação pode gerar uma economia de milhões.

\section{Agradecimentos}

Aos colaboradores que ajudaram incondicionalmente o projeto em suas fases de testes e aos que incentivaram e colaboraram de forma técnica, teoria e incentivadora. Em especial a toda a equipe GNA, GNM e GLO.

\section{BIBLIOGRAFIA}

1 SERRA. Modelagem da formação de porosidades na solidificação de tarugos pelo programa thermo-calc. 